\title{
Smooth Muscle $\alpha$-Actin Deficiency Leads to Decreased Liver Fibrosis via Impaired Cytoskeletal Signaling in Hepatic Stellate Cells
}

\author{
Don C. Rockey, Qinghong Du, and Zengdun Shi
}

From the Department of Internal Medicine, Medical University of South Carolina, Charleston, South Carolina

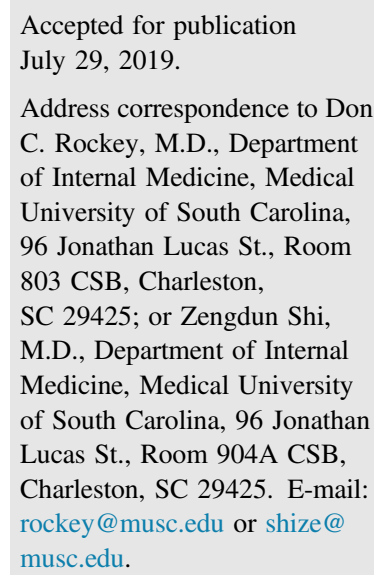

\begin{abstract}
In the liver, smooth muscle $\alpha$-actin (SM $\alpha$-actin) is up-regulated in hepatic stellate cells (HSCs) as they transition to myofibroblasts during liver injury and the wound healing response. Whether SM $\alpha$-actin has specific functional effects on cellular effectors of fibrosis such as HSC is controversial. Here, the relationship between SM $\alpha$-actin and type 1 collagen expression (COL1A1), a major extracellular matrix protein important in liver fibrosis, is investigated with the results demonstrating that knockout of SM $\alpha$-actin leads to reduced liver fibrosis and COL1 expression. The mechanism for the reduction in fibrogenesis in vivo is multifactorial, including not only a reduction in the number of HSCs, but also an HSC-specific reduction in COL1 expression in Acta2-deficient HSCs. Despite a compensatory increase in expression of cytoplasmic $\beta$-actin and $\gamma$-actin isoforms in Acta2 ${ }^{-1-} \mathrm{HSC}$, defects were identified in each transforming growth factor beta/Smad2/3 and ET-1/Erk1/2 signaling in Acta2 $^{-/-}$HSCs. These data not only suggest a molecular link between the SM $\alpha$-actin cytoskeleton and classic fibrogenic signaling cascades, but also emphasize the relationship between SM $\alpha$-actin and fibrogenesis in hepatic myofibroblasts in vivo. (Am J Pathol 2019, 189: 2209-2220; https://doi.org/10.1016/ j.ajpath.2019.07.019)
\end{abstract}

Fibrosis is a wound healing response to injury and characterized by excessive synthesis and accumulation of extracellular matrix (ECM) proteins in many organs such as skin, liver, lung, kidney, and heart, which ultimately leads to organ failure and death. ${ }^{1,2}$ Pathologically, myofibroblasts are the major cellular source of ECM in most forms of fibrogenesis, ${ }^{3}$ despite the fact that myofibroblasts may originate from various cell types depending on the organ and mechanism of injury. ${ }^{4}$ For example, myofibroblasts in pulmonary fibrosis may originate from interstitial lung fibroblasts, lipofibroblasts, pericytes, and mesothelial cells. ${ }^{5}$ By contrast, myofibroblasts in liver fibrosis originate primarily from hepatic stellate cells (HSCs). ${ }^{6,7}$ Nevertheless, myofibroblasts share two common features-de novo expression of smooth muscle $\alpha$-actin (SM $\alpha$-actin) and abundant ECM, particularly type 1 collagen (COL1A1).

Actins consist of six isoforms and play an essential role in many cell processes, including cell proliferation, differentiation, migration, and contraction. ${ }^{8,9} \mathrm{SM} \alpha$-actin appears to play an important functional role in myofibroblast contraction and migration. ${ }^{10,11}$ Previous studies have shown that stress fibers containing SM $\alpha$-actin, not only generate greater contractile force than stress fibers that contain only cytoplasmic- $\beta$ and $\gamma$-actin, ${ }^{12}$ but also associate with supermature focal adhesions, which in turn exhibit a specific molecular composition of vinculin, paxillin, tensin, and integrins $\alpha v \beta 3$ and $\alpha 5 \beta 1 .^{13,14}$ Integrins are transmembrane proteins, and thus integrins can bidirectionally transmit the mechanical signal across the cell membrane. ${ }^{15}$ Although the molecular mechanisms by which the mechanical signal regulates extracellular matrix expression remain unclear, studies have revealed that the cell contractile force (mediated by actin stress fibers), as a mechanical signal, could be transformed to a chemical signal to modulate ECM genes

Supported by NIH grants R01 DK 098819 (D.C.R.) and DK113159 (D.C.R.).

Disclosures: None declared.

Current address of Q.D., Beijing University of Chinese Medicine, Beijing, China. 
such as COL1Al expression through transforming growth factor- $\beta$ (TGF- $\beta$ ) and Erk signal pathways. ${ }^{16-18}$ Although multiple evidence supports that SM $\alpha$-actin plays an important role in multiple features of myofibroblasts, SM $\alpha$-actin's role in fibrogenesis remains controversial. ${ }^{19}$

In the present study, it was hypothesized that SM $\alpha$-actin has direct and indirect effects on COL1 synthesis in HSCs. Acta2-deficient mice and adenovirus-mediated overexpression of SM $\alpha$-actin in rat HSCs were used to explore the role of SM $\alpha$-actin in vivo and the molecular mechanisms via which SM $\alpha$-actin regulates the synthesis of the ECM. The results demonstrate that Acta2 deficiency has significant effects on HSC-mediated ECM synthesis and uncovered a link between SM $\alpha$-actin and fibrogenesis in activated HSCs (myofibroblasts).

\section{Materials and Methods}

\section{Animal Model, Cell Isolation, and Culture}

Acta2-deficient mice on a BALB/c background were obtained by embryo transfer by mating Acta2-deficient $129 \mathrm{SV} /$ C57 background male mice (a kind gift from Dr. Robert Schwartz ${ }^{20}$ ) with BALB/c inbred female mice (Jackson Laboratory, Bar Harbor, ME); offspring were crossed with $\mathrm{BALB} / \mathrm{c}$ mice for six generations. Hepatic wounding was induced in male mice (9 to 10 weeks old) by repetitive intragastric administration of carbon tetrachloride (six doses) as described. ${ }^{21}$ Controls received corn oil on the same schedule as experimental animals (wild-type and Acta2-null mice were randomly divided into two groups: normal control and carbon tetrachloride treatment). All animals received care according to $\mathrm{NIH}$ guidelines and the animal care committee-approved protocol from the Medical University of South Carolina.

HSCs were isolated from normal and injured male mice (3 to 4 months old) or normal retired breeder male rats (500 to $550 \mathrm{~g}$; Charles River Laboratory, Wilmington, MA) and cultured in 1990R standard medium as described. ${ }^{18}$ Cell purity ( $>98 \%$ ) was assessed by intrinsic vitamin A autofluorescence as described. ${ }^{22}$

\section{Adenovirus}

Adenovirus harboring a full-length mouse Acta2 cDNA (encoding 377aa; https://www.ncbi.nlm.nih.gov/genbank; GenBank accession number X13297) was generated as previously described. ${ }^{23}$ For adenovirus-flag-MRTF-A expression vector, a full-length MRTF-A (https://www.ncbi. nlm.nih.gov/genbank; GenBank accession number AF532597) was cloned from mouse activated HSCs by PCR approach (forward primer with KpnI site: 5'-TAGGTACCTCC GCCTTTGAAAAGCCCCGCT-3'; reverse primer with XhoI site: 5'-CACTCGAGCTACAAGCAGGAATCCCAG TGGAG- $3^{\prime}$ ). The resulting DNA fragments were first ligated into the $\mathrm{KpnI} / \mathrm{XhoI}$ sites of pcDNA3.1-flag plasmid vector.
Following digestion with HindIII/XhoI, the fragments containing flag-MRTF-A were inserted into the HindIII/XhoI sites of a modified pDC316 shuttle vector (PD-01-28; Microbix, Toronto, ON, Canada) with pCMV promoter. ${ }^{18}$ The resulting pDC316-flag-MRTF-A plasmid was cotransfected with pBGHlox $\Delta \mathrm{E} 1,3$-cre viral plasmid (Microbix) into 293HEK cells to generate adenovirus-flag-MRTF-A (Ad-MRTF-A). Adenovirus-CMV empty control (Ad-control) was purchased from Vector BioLabs (Malvern, PA).

\section{Real-Time Quantitative PCR}

Total RNA was extracted from whole liver or isolated HSCs with TRIzol (Invitrogen, Carlsbad, CA), and cDNA was generated using a Superscript III Reverse Transcriptase kit (Invitrogen) according to the manufacturer's instructions. Real-time quantitative PCR was performed on a Bio-Rad iQ5 Multicolor Real-Time PCR Detection System using iQ supermix (Bio-Rad, Hercules, CA) with specific primers (Table 1).

\section{Immunoblot}

Immunoblotting to detect SM $\boldsymbol{\alpha}$-actin was performed as described. ${ }^{22}$ Specific signals were captured by the Syngene G:Box digital imaging system (Chemi XT4; Syngene, Frederick, MD), and quantitative data were obtained from the system's software. Raw values for control samples were arbitrarily set to 1 (or 100\%), and data were presented as relative expression at fold change of control. Anti-SM $\alpha$-actin (1A4), $\beta$-actin (AC15), and skeletal $\alpha$-actin (5C5) antibodies

Table 1 Real-Time Quantitative PCR Primer Sequences

\begin{tabular}{|c|c|}
\hline Gene names & Sequences \\
\hline \multirow[t]{2}{*}{ Col1al (mouse/rat) } & F: 5'-TCAGCCACCTCAAGAGAAGTC-3' \\
\hline & R: 5'-CTGCGGATGTTCTCAATCTGC-3' \\
\hline \multirow[t]{2}{*}{ Acta2 (mouse/rat) } & F: 5'-GTGTGAAGAGGAAGACAGCAC-3' \\
\hline & R: 5'-GTGATGATGCCGTGTTCTATCG-3' \\
\hline \multirow[t]{2}{*}{ Actb (mouse) } & F: 5'-GATGACGATATCGCTGCGC-3' \\
\hline & R: 5'-TGGTAACAATGCCATGTTCAATGG-3' \\
\hline \multirow[t]{2}{*}{ Actg1 (mouse) } & F: 5'-GAAGAAGAAATCGCCGCACTC-3' \\
\hline & R: 5'-AGTGACAATGCCGTGTTCGATAG-3' \\
\hline \multirow[t]{2}{*}{ Tgfb (mouse) } & F: 5'-TGGCGTTACCTTGGTAACCG-3' \\
\hline & R: 5'-TTGCTGTCACAAGAGCAGTGAG-3' \\
\hline \multirow[t]{2}{*}{ Edn1 (mouse) } & F: 5'-TCTGACСССTTTGCAGAATGG-3' \\
\hline & R: 5'-TCTGCACTCCATTCTCAGCTC-3' \\
\hline \multirow[t]{2}{*}{ Timp1 (mouse) } & F: 5'-CATCTCTGGCATCTGGCATCC-3' \\
\hline & R: 5'-TCTCGTTGATTTCTGGGGAACC-3' \\
\hline \multirow[t]{2}{*}{ Gfap (mouse) } & F: 5'-GATGAAACCAACCTGAGGCTG-3' \\
\hline & R: 5'-TCTCTCCAAATCCACACGAGC-3' \\
\hline \multirow[t]{2}{*}{ TNFA } & F: 5'-TGCCTATGTCTCAGCCTCTTC-3' \\
\hline & R: 5'-CACTTGGTGGTTTGCTACGAC- $3^{\prime}$ \\
\hline \multirow[t]{2}{*}{ Il6 (mouse) } & F: 5'-GTTGCCTTCTTGGGACTGATG-3' \\
\hline & R: 5'-TAAGCCTCCGACTTGTGAAGTG-3' \\
\hline \multirow[t]{2}{*}{ Gapdh (mouse/rat) } & F: 5'-TGCACCACCAACTGCTTAGC-3' \\
\hline & R: 5'-GGCATGGACTGTGGTCATGAG-3' \\
\hline
\end{tabular}

$F$, forward; $R$, reverse. 
were from Sigma-Aldrich (St. Louis, MO). Anti-cytoplasmic $\gamma$-actin (AB3265) and GAPDH (GA1R, MA5-15738) were from Millipore (Temecula, CA) and Thermo Fisher Scientific (Rockford, IL), respectively. GAPDH is not suitable as a loading control in experiments comparing quiescent and activated HSCs because GAPDH is significantly up-regulated during HSC activation. TGF- $\beta$ (cyt-716) and ET-1 (88-1-10) were from ProSpec-Tany TechnoGene (Ness Ziona, Israel) and American Peptide Company (Sunnyvale, CA), respectively. Anti-COL1 antibody (600-401-103-0.5) was from Rockland (Gilbertsville, PA). Anti-phosphor-Smad2 (138D4, 3108S) (p-Smad2/3) and total Smad2 (D43B4, 5339S) (T-Smad2), phosphor-Erk1/2 (9101S), and Erk1/2 (9102S) antibodies were from Cell Signaling Technology (Danvers, MA). The MRTF-A/SRF inhibitor, CCG-203971, and latrunculin-B were from Cayman Chemical (Ann Arbor, MI) and Calbiochem (San Diego, CA), respectively. Coomassie Blue R-250 (161-0438) was from Bio-Rad.

\section{Cell Contraction/Proliferation/Wound Healing Assay}

HSCs $\left(1 \times 10^{5}\right.$ cells/well $)$ were isolated and grown on 24 well plates that had been seeded with collagen gel lattices (5005-B; Advanced BioMatrix, San Diego, CA), and contraction was performed as described. ${ }^{18}$ Quiescent HSCs were seeded and grown on a 96-well plate in standard medium for 3 days and then incubated in $0.5 \%$ serum medium with or without PDGF-BB (10 ng/mL, CYT-501; ProSpec, East Brunswick, NJ) for 2 more days. The assay was performed using a CellTiter $96 \mathrm{AQ}_{\text {ueous }}$ One Solution Cell Proliferation Assay Kit (MTS, G3582; Promega, Madison, WI) as before. ${ }^{11}$ Wound healing assay (CBA-120; Cell Biolabs, San Diego, CA) was performed as described. ${ }^{18}$

\section{Actin Polymerization Assay}

Globular-actin/filamentous-actin (G/F-actin) was measured according to the manufacturer's instructions (BK037; Cytoskeleton, Denver, CO). In brief, after incubating cell lysates at $37^{\circ} \mathrm{C}$ for 10 minutes, the total protein concentration was assayed, and $100 \mu \mathrm{g}$ per sample was subjected to further analysis as described. Finally, $20 \mu \mathrm{L}$ of each sample from the supernatant G-actin or the depolymerized actin pellet F-actin was subjected to immunoblotting using anti(total) actin antibody. Images were captured and analyzed by ImageJ software version $1.46(\mathrm{NIH}$, Bethesda, MD; http://imagej.nih.gov/ij); results were presented as the relative expression of actin and the ratio of F-actin/G-actin.

\section{Immunocytochemistry/Immunohistochemistry/0il Red 0 Staining}

HSCs were grown on glass coverslips (12CIR-1D; Thermo Fisher Scientific) and immunofluorescence staining was performed as described. ${ }^{18}$ Anti-SM $\alpha$-actin antibody conjugated with $\mathrm{Cy} 3$ (C6198) and anti- $\beta$-actin (AC15) were purchased from Sigma-Aldrich. Anti-cytoplasmic- $\gamma$-actin isoform (AB3265) antibody was from Millipore. Anti-CRBP-1 (FL-135) was purchased from Santa Cruz Biotechnology (Dallas, TX). Alexa Fluor 488 donkey antisheep (A11015) and Fluor 555 goat anti-rabbit (A21428) or mouse (A21422) antibodies were obtained from Life Technology (Carlsbad, CA). DRAQ5 and DAPI were obtained from Thermo Fisher Scientific. In brief, for immunohistochemistry and histochemistry, liver tissues were fixed and embedded in paraffin, and 5- $\mu \mathrm{m}$ sections were subjected to sodium citrate antigen retrieval; immunofluorescence staining was as described. ${ }^{23}$ Images were captured with a Zeiss Axio Imager M2 (Zeiss, Oberkochen, Germany). Sections stained with Picrosirius Red (Sigma-Aldrich) were counterstained with Fast Green FCF (Sigma-Aldrich). Images were captured with a Nikon Digital Imaging microscope (Nikon, Tokyo, Japan), and collagen content was assessed by morphometric analysis as described. ${ }^{18}$ To examine the lipid droplets in HSCs, HSCs were grown on plastic culture dishes and Oil Red O (MAK194; Sigma-Aldrich) staining was performed as described. ${ }^{24}$

\section{Statistics}

One-way analysis of variance (more than two groups) and two-tailed $t$-test (two groups) were used for statistical comparisons. Bar graphs represent means \pm SD. $P<0.05$ was considered statistically significant.

\section{Results}

SM $\alpha$-Actin Deficiency Leads to Up-Regulation of Other Actin Isoforms in HSCS

Myofibroblasts from different tissue sources may have different actin isoform expression patterns, ${ }^{19,25}$ which directly link to actin stress fiber composition. Thus, actin isoform profile and expression patterns were examined at the mRNA and protein levels. The results from real-time quantitative PCR showed that mRNA levels of cytoplasmic $\gamma$-actin and $\beta$-actin were up-regulated in Acta2-deficient $\left(\right.$ Acta2 $^{-/-}$) HSCs during culture-induced activation. As previously reported, SM $\alpha$-actin mRNA was almost undetectable in Acta2-deficient myofibroblasts ${ }^{19}$ (Figure 1A). At the protein level, SM $\alpha$-actin was robustly increased in wild-type Acta 2 $\left(\mathrm{Acta}^{+/+}\right.$) HSCs during cell culture-induced activation. In contrast to $\mathrm{Acta} 2^{+/+}$stellate cells, there was an increase in cytoplasmic $\gamma$-actin and $\beta$-actin isoforms during activation in Acta $2^{-/-}$HSCs (Figure 1B and Supplemental Figure S1). Coomassie Blue staining was used as a protein loading control because GAPDH is also increased during stellate cell activation. Surprisingly, unlike myofibroblasts from kidney fibrosis and skin wound healing, ${ }^{19,25}$ mouse HSCs did not express smooth muscle $\gamma$-actin (SM $\gamma$-actin) and skeletal $\alpha$-actin isoforms (Figure 1C). These data demonstrate that 

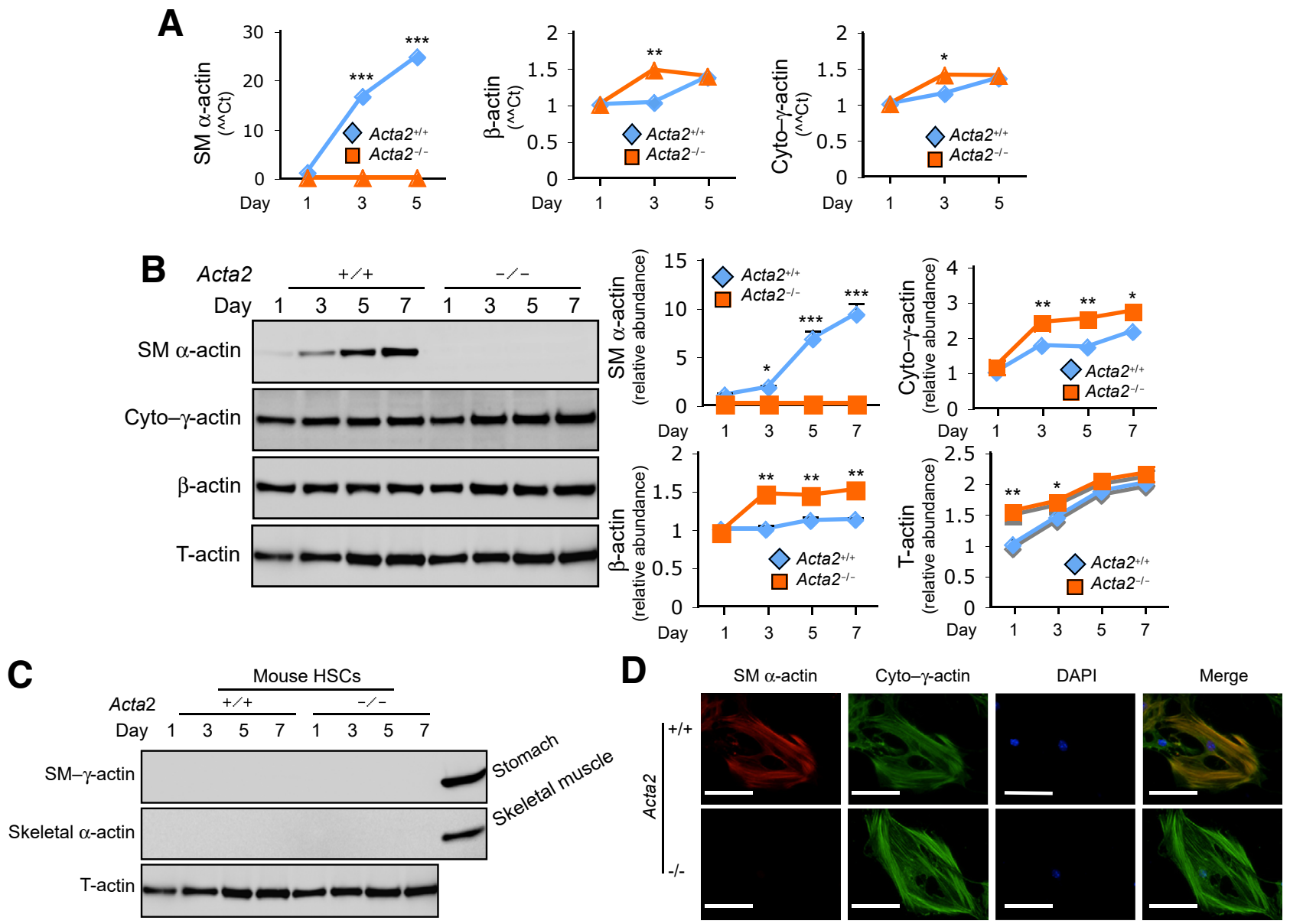

Figure 1 Actin isoform profiling in $\mathrm{Acta2}^{-/-}$and $\mathrm{Acta2}^{+/+}$hepatic stellate cells. Hepatic stellate cells (HSCs) were isolated from normal Acta2 wild-type $(+/+)$ and Acta2-deficient (-/-) mouse livers and allowed to undergo culture-induced activation as indicated. A: Total RNA was isolated and actin isoform mRNA levels were measured by real-time quantitative PCR using isoform-specific primers. B and C: Cells were isolated as in A, and whole-cell lysates were immunoblotted with specific antibodies. Representative images and quantitative data are shown. Coomassie Blue staining was used to verify appropriate loading (Supplemental Figure S1). D: Cells were isolated as in $\mathbf{A}$ and cultured on glass coverslips for 7 days, and then the cells were subjected to immunofluorescence staining. Data are expressed as $\Delta \Delta \mathrm{C}_{\mathrm{t}} . n=3 .{ }^{*} P<0.05,{ }^{*} P<0.01$, and ${ }^{* *} * P<0.001$ for Acta2 ${ }^{+/+}$versus $A c t a 2^{-/-}$. Scale bars $=40 \mu \mathrm{m}$. cyto- $\gamma$-actin, cytoplasmic $\gamma$-actin.

mouse HSCs/myofibroblasts express only three actin isoforms-SM $\alpha$-actin, cytoplasmic $\gamma$-actin, and $\beta$-actin. ${ }^{23}$

Finally, the actin cytoskeleton in $\mathrm{Acta}^{-/-}$and $\mathrm{Acta} 2^{+/+}$ stellate cells was examined with immunofluorescence microscopy (Figure 1D). Acta2 $2^{-/-}$stellate cells have wellorganized actin stress fibers consisting of cytoplasmic $\gamma$-actin and $\beta$-actin isoforms but lack SM $\alpha$-actin stress fibers. Consistent with the actin isoform expression profile, there were more prominent cytoplasmic $\gamma$-actin and $\beta$-actin isoforms in $A c t a 2^{-/-}$stellate cells than in wild-type stellate cells (Figure 1D and Supplemental Figure S2). These data indicate that there is a compensatory up-regulation of cytoplasmic $\gamma$-actin and $\beta$-actin isoforms in $A c t a 2^{-/-}$stellate cells.

\section{SM $\alpha$-Actin Deficiency Alters HSC Function}

A prominent functional result of the de novo expression of SM $\alpha$-actin in myofibroblasts is increased cellular contraction. ${ }^{12}$ Thus, the effect of $\mathrm{Acta}^{-{ }^{-}-}$was examined on stellate cell contractility. As expected, stellate cell contraction was significantly reduced in $A c t a 2^{-/-}$compared with $A c t a 2^{+/+}$stellate cells (Figure 2A). Next, the cell response to TGF- $\beta$ and ET-1 was examined because both TGF- $\beta$ and ET- 1 induce cell contraction. ${ }^{26,27} \mathrm{Acta}^{+/+}$stellate cells exhibited more robust contraction in response to either TGF- $\beta$ or ET- 1 stimulation (Figure 2, B and C); both the temporal contractile response and the cumulative response were greater in $\mathrm{Acta} 2^{+/+}$than Acta2 $^{-1-}$ stellate cells. Additionally, the effect of overexpression of MRTF-A (which has been shown to increase actin polymerization-stress fiber formation) on stellate cell contraction was examined. Interestingly, MRTF-A increased both $\mathrm{Acta}^{+/+}$and $\mathrm{Acta2} 2^{-/-}$stellate cell contractility, but $\mathrm{Acta}^{2 /+}$ stellate cells exhibited more prominent contraction than $A c t a 2^{-/-}$stellate cells (Figure 2D). The effect of Acta2 deficiency on HSC proliferation was further examined. Three different assays with low, medium, and high numbers of HSCs were performed. In this in vitro cell culture system, an alteration in proliferation in Acta2 $^{-1-}$ HSCs was not observed 


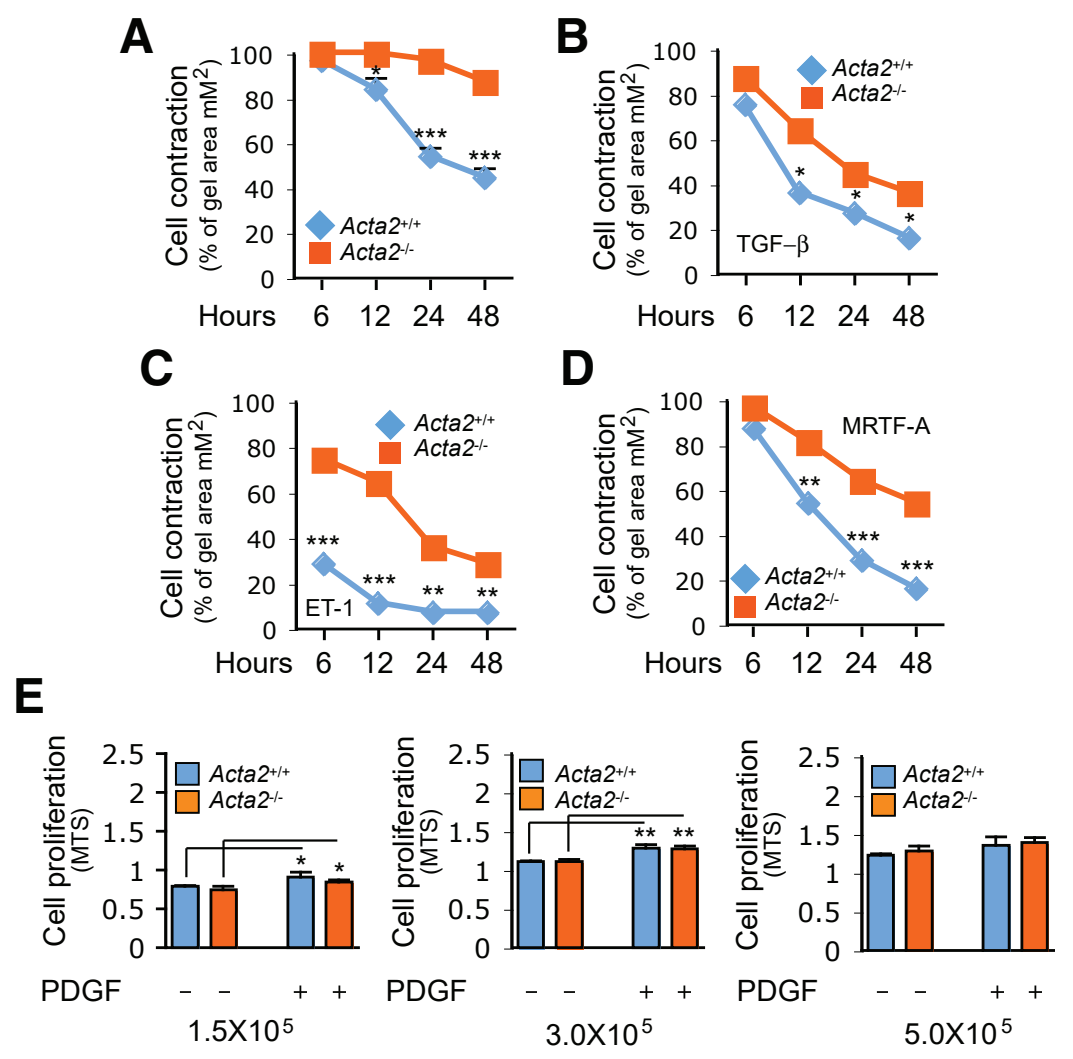

Figure 2 Impaired hepatic stellate cellular contractility in Acta2-deficient cells. A-C: Hepatic stellate cells (HSCs) from $\mathrm{Acta}_{2}{ }^{+/+}$and $\mathrm{Acta}^{-/-}$mice were cultured in standard medium for 5 days and then incubated in $0.5 \%$ serum medium with or without $10 \mathrm{ng} / \mathrm{mL}$ TGF- $\beta$ or 20 $\mu \mathrm{mol} / \mathrm{L}$ ET-1 for 24 hours before dislodging gel lattices. Gel contraction was measured at different time points as indicated. D: Hepatic stellate cells from $\mathrm{Acta2}^{+/+}$and Acta2 $^{-/-}$mice were exposed to Ad-control or Ad-flagMRTF-A (25 multiplicity of infection) for 3 days and then incubated in $0.5 \%$ serum medium for 24 hours before dislodging gel lattices; gel contraction was measured as in A. E: Cells were isolated as in A and placed in 96-well plates at the indicated cell concentrations. Following 3 days of growth, cells were changed to $0.5 \%$ serum medium with or without $10 \mathrm{ng} / \mathrm{mL}$ PDGF-BB for a further 2 days. Cell proliferation was measured as described in Materials and Methods. $n=3 .{ }^{*} P<0.05,{ }^{*} P<0.01$, and ${ }^{* *} P<0.001$ for $\mathrm{Acta}^{+/+}$versus Acta2 $^{-/-}$. MTS, 3(4,5-dimethylthiazol-2-yl)-5-(3-carboxymethoxyphenyl)2-(4-sulfophenyl)-2H-tetrazolium, inner salt.
(Figure 2E). Finally, a wound-healing assay was performed to determine the effect of $A c t a 2^{-1-}$ on HSC migration. Minor differences were found only in cell migration when comparing Acta $^{-/-}$and Acta2 ${ }^{+/+}$HSCs (Supplemental Figure S3). Taken together, these data suggest that $\mathrm{SM} \alpha$-actin in HSCs plays a critical role in cell contraction/cytoskeletal tension generation, but it does not play a major role in cell proliferation and migration, which is consistent with evidence that suggests that cytoplasmic $\beta$-actin is most important in control of cell growth and migration. ${ }^{28}$

Other functional features that might be associated with SM $\alpha$-actin expression were also studied. Quiescent HSCs from $\mathrm{Acta}^{-/-}$and $\mathrm{Acta} 2^{+/+}$mice appeared to be similar in cell size and showed similar lipid droplet content (Figure 3A). Fully activated HSCs from $A c t a 2^{-/-}$mice also exhibited a similar size and shape as $\mathrm{Acta}^{+/+}$HSCs (Figure 3A). Oil Red O staining revealed that $\mathrm{Acta}^{-/-}$and Acta $^{+/+}$HSCs had similar amounts of lipid droplets in their cytoplasm (Figure 3B).

Gene expression in activated HSCs was examined next. There was a difference in expression of GFAP and TIMP1 mRNA in quiescent Acta2 $2^{-/-}$and Acta2 $2^{+/+}$HSCs (Figure 3C). However, GFAP and TIMP1 mRNA levels were prominently decreased in activated $A c t a 2^{-1-}$ HSCs. Similarly, TGF- $\beta$ and ET- 1 mRNA levels were both reduced in $A c t a 2^{-l-}$ HSCs (Figure 3C). The role of SM $\alpha$-actin in modulating COL1 $\alpha 1$ expression was further examined by stimulating
HSCs with TGF- $\beta$ and ET-1, because both are well known to increase COL $1 \alpha 1$. Following TGF- $\beta$ or ET- 1 stimulation, both Acta $^{-/-}$and Acta2 ${ }^{+/+}$HSCs had significantly increased COL1 $\alpha 1$ mRNA expression. However, the response in Acta $^{-1-}$ HSCs was significantly less than that in Acta $2^{+/+}$ HSCs (Figure 3D). In addition, even without stimulation, COL $1 \propto 1$ mRNA expression was reduced in Acta $2^{-1-}$ HSCs compared with Acta2 ${ }^{+/+}$cells (these cells had been exposed to serum, which is known to stimulate COL1 $\alpha 1$ expression).

Finally, SM $\alpha$-actin was overexpressed in rat stellate cells to directly examine the effect of SM $\alpha$-actin on COL1 expression. Increased SM $\alpha$-actin levels robustly upregulated COL1 expression (Figure 3E). Interestingly, more aggressive overexpression of SM $\alpha$-actin [ie, with $>50$ multiplicity of infection (MOI) adenovirus] did not increase COL1 expression as much as less prominent overexpression.

\section{SM $\alpha$-Actin Signals to Smad2/3 and Erk1/2 Pathways}

Among the multiple signaling pathways prominent during hepatic stellate cell activation, the TGF- $\beta / \mathrm{Smad} 2 / 3$ and ET1/Erk1/2 pathways are among the most notable. ${ }^{29,30}$ Stellate cells not only express TGF- $\beta$ and ET-1 receptors, but they also produce TGF- $\beta$ and ET-1 in an autoregulatory loop, which stimulates activation and myofibroblast phenotypic differentiation. $^{1,30}$ Thus, the TGF- $\beta$ and ET-1 pathways 
A
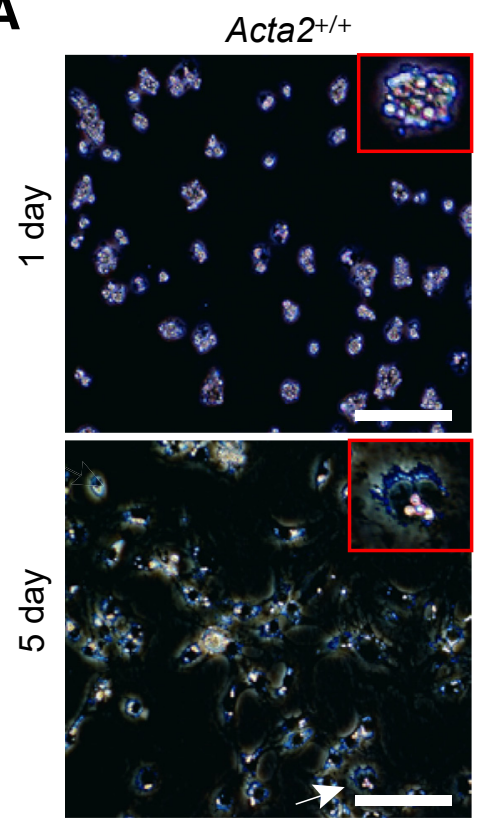

B
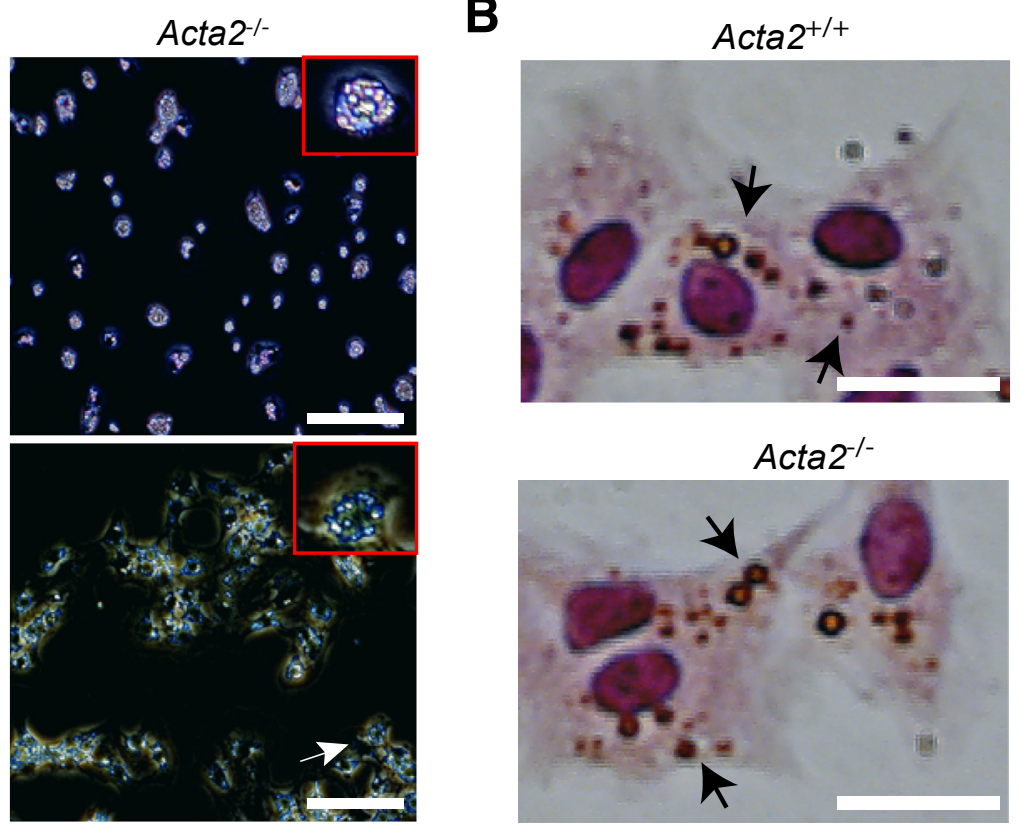

C
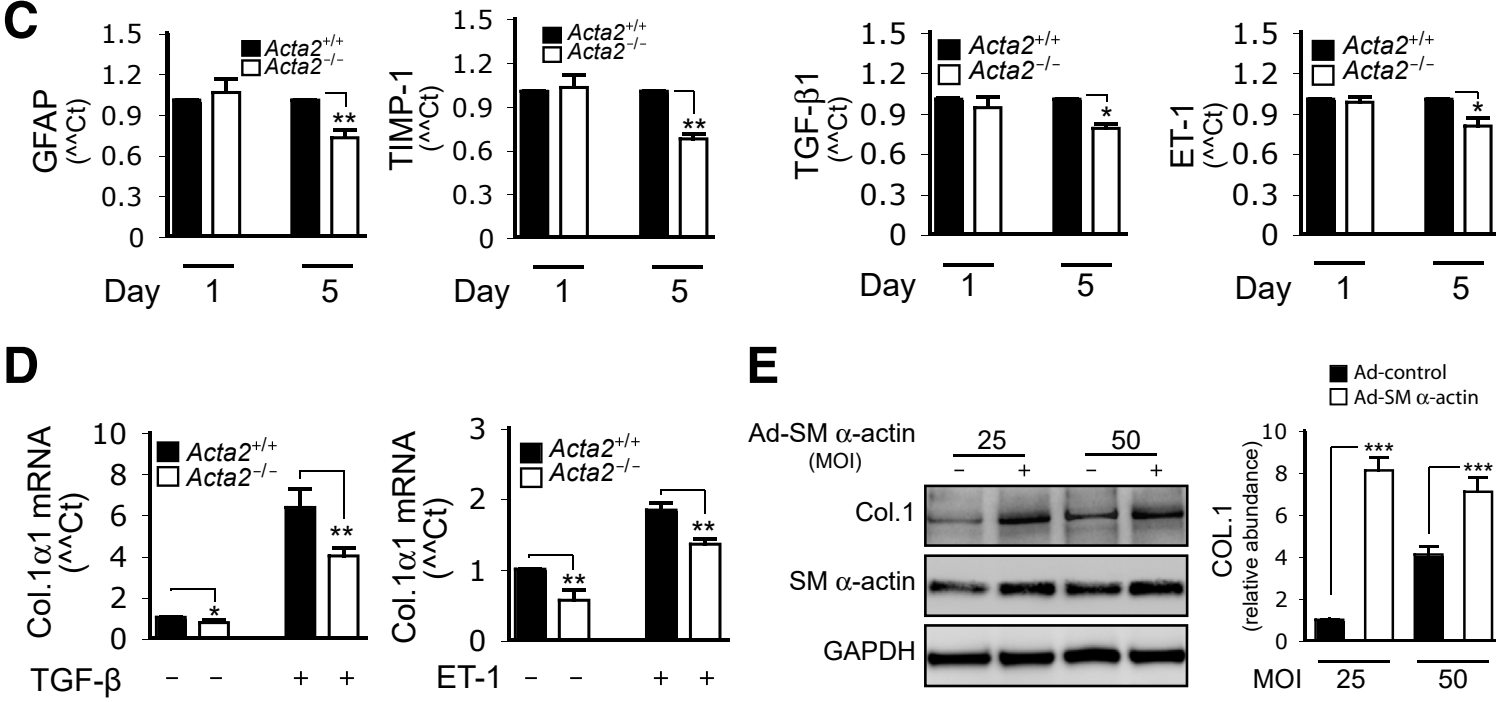

$\mathbf{E}$

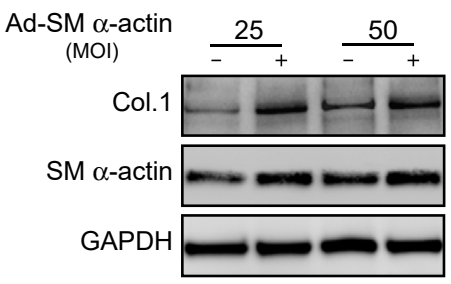

Ad-control $\square$ Ad-SM $\alpha$-actin

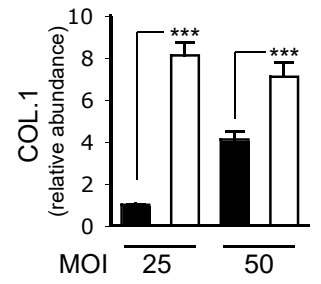

Figure 3 Cellular features and COL1 expression of smooth muscle (SM) $\alpha$-actin-deficient hepatic stellate cells (HSCs). A: HSCs from Acta2 ${ }^{+/+}$and Acta $^{-1-}$ mice were cultured in standard medium as indicated, and images were captured using darkfield phase microscopy. The arrows indicate an individual HSC, and the insets show a higher magnification (representative images are shown from $>10$ others). B: Cells were cultured as in $\mathbf{A}$ for 3 days and subjected to 0il Red 0 staining. The arrows indicate cytoplasmic lipid droplets in HSCs (representative images are shown of $>10$ others). C: Cells were as in $\mathbf{A}$, and total RNA was isolated. Real-time quantitative PCR was performed to detect the indicated mRNAs. D: Cells were cultured as in $\mathbf{A}$ for 5 days and then incubated in $0.5 \%$ serum medium with or without $10 \mathrm{ng} / \mathrm{mL} \mathrm{TGF}-\beta$ or $20 \mu \mathrm{mol} / \mathrm{L} \mathrm{ET-1}$ for 24 hours. Total RNA was isolated, and COL1 $\alpha 1 \mathrm{mRNA}$ levels were measured by real-time quantitative PCR. E: Rat hepatic stellate cells were exposed to Ad-control or Ad-SM $\alpha$-actin [25 or 50 multiplicity of infection (MOI)] for 3 days in $0.5 \%$ serum medium and then incubated in $0.5 \%$ serum medium for an additional 1 day; whole-cell lysates were subjected to immunoblotting as indicated, and the quantitative data were presented graphically. $n=3 .{ }^{*} P<0.05,{ }^{* *} P<0.01$, and ${ }^{* * *} P<0.001$ for Acta2 ${ }^{+/+}$versus Acta2 $^{-1-}$. Scale bars: $20 \mu \mathrm{m}($ A); $40 \mu \mathrm{m}$ (B). Original magnification, $\times 20$ (insets).

were examined in $A c t a 2^{-1-}$ HSCs. Upon stimulation with TGF- $\beta$, Smad2/3 phosphorylation (p-Smad2/3) was prominently increased early in both Acta $2^{+/+}$and $\mathrm{Acta}^{-/-} \mathrm{HSCs}$ (Figure 4A). However, p-Smad2/3 levels remained at significantly higher levels in $\mathrm{Acta} 2^{+/+}$HSCs than in Acta2 $^{-l-}$ HSCs at later time points stage (ie, 6 to 9 hours following the stimulation) (Figure 4A).
Next, Erk1/2 phosphorylation (p-Erk1/2) was examined after ET-1 stimulation (Figure 4B). Erk1/2 phosphorylation was rapid in $\mathrm{Acta} 2^{+/+}$HSCs after ET-1 exposure and was maintained up to 1 hour. By contrast, Erk1/2 phosphorylation in $A c t a 2^{-1-}$ HSCs was prominently delayed and weaker.

Finally, the direct effect of SM $\alpha$-actin on $\operatorname{Smad} 2 / 3$ phosphorylation was examined. Indeed, overexpression of 


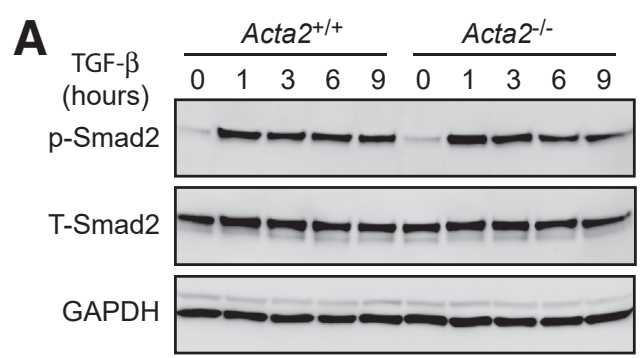

B

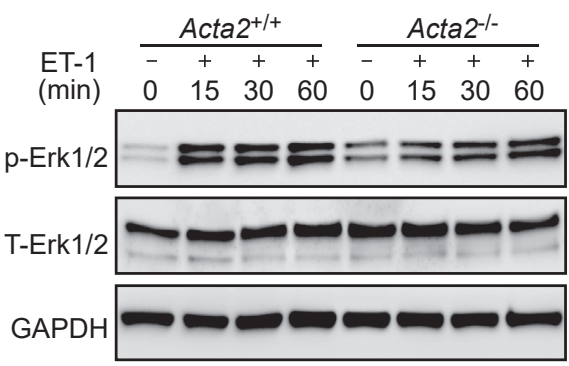

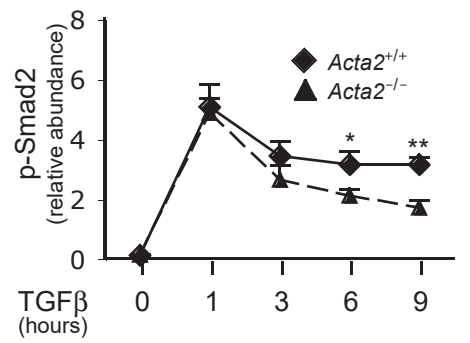

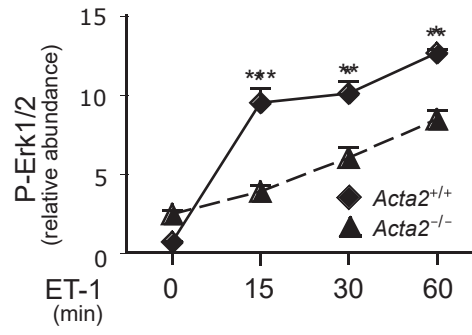

C

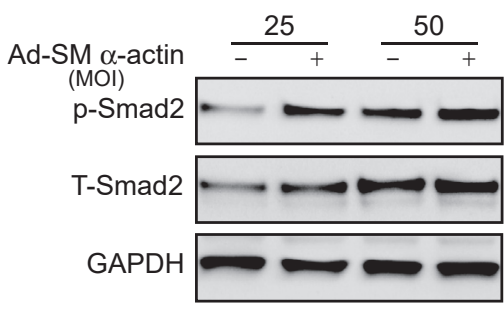

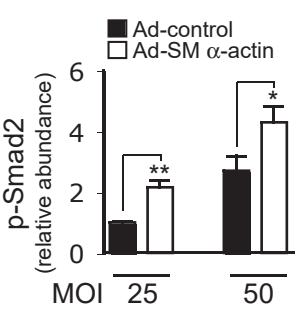

Figure 4 Smooth muscle (SM) $\alpha$-actin regulates Smad2 and Erk1/2 phosphorylation. $\mathbf{A}$ and $\mathbf{B}$ : Hepatic stellate cells (HSCs) from $\mathrm{Acta}^{+/+}$and Acta2 $^{-1-}$ mice were cultured in standard medium for 5 days and then incubated in $0.5 \%$ serum medium for 24 hours. Cells were stimulated with $10 \mathrm{ng} / \mathrm{mL}$ TGF- $\beta$ or $20 \mu \mathrm{mol} / \mathrm{L} \mathrm{ET-1}$ at indicated time points. Whole-cell lysates were subjected to immunoblotting as indicated, and quantitative data are shown graphically. C: Rat hepatic stellate cells were exposed to Ad-control or Ad-SM $\alpha$-actin [25 or 50 multiplicity of infection (MOI)] for 3 days in $0.5 \%$ serum medium and then incubated in $0.5 \%$ serum medium for 24 hours. Endogenous pSmad2 levels were measured by immunoblotting as indicated, and quantitative data are presented graphically. $n=3 .{ }^{*} P<0.05,{ }^{*} P<0.01$, and ${ }^{* * * P}<0.001$ for $\mathrm{Acta2}^{+/+}$versus Acta2 $^{-/-}$.
SM $\alpha$-actin in activated rat stellate cells stimulated $\mathrm{p}$-Smad2 (Figure 4C), consistent with the stimulation of COL1 expression after overexpression of SM $\alpha$-actin (Figure 3D).

\section{SM $\alpha$-Actin Polymerization Mediates Mechanotransduction in HSCS}

Actin consists of globular-actin (G-actin) and filamentousactin (F-actin). ${ }^{8}$ It was hypothesized that SM $\alpha$-actin-induced COL1 expression (Figure 3E) and phosphorylation of Smad2/3 and Erk1/2 (Figure 4) are a result of increased SM $\alpha$-actin polymerization (which is reflected in an increased $\mathrm{F} /$ G-actin ratio). Thus, the effect of overexpression of SM $\alpha-$ actin on F/G-actin was first examined in rat HSCs. SM $\alpha$ actin overexpression promoted SM $\alpha$-actin polymerization and led to a significantly increased F/G-actin ratio (Figure 5, A and B). Interestingly, cytoplasmic $\gamma$-actin polymerization was prominently decreased after SM $\alpha$-actin overexpression (after 25 MOI Ad-Acta2), and both G-actin and F-actin were reduced after 50 MOI Ad-Acta2 (Figure 5, A and C). By contrast, $\beta$-actin polymerization increased slightly (Figure 5 , $\mathrm{A}$ and $\mathrm{D})$. In aggregate, the data raise the possibility that SM $\alpha$-actin up-regulation (and F-actin polymerization) is important functionally, and moreover, are consistent with enhanced HSC's contractility typical of stellate cell activation.
Finally, the effects of blocking actin polymerization on the Smad2/3 and Erk1/2 signaling cascades were examined using CCG-203971 (a specific MRTF-A inhibitor) and latrunculin-B (a specific actin polymerization inhibitor). p-Smad $2 / 3$ was robustly increased in both $\mathrm{Acta}^{-1-}$ and $\mathrm{Acta}^{+/+}$HSCs after TGF- $\beta$ stimulation for 1 hour, which was essentially abrogated by CCG-203971 (Figure 5E). However, Acta $2^{+/+}$HSCs exhibited significantly higher levels of $\mathrm{p}-\mathrm{Smad} 2 / 3$ than Acta2 $^{-/-}$HSCs in the presence of latrunculin-B. Following ET-1 stimulation for 30 minutes, $\mathrm{p}$-Erk1/2 was dramatically increased in both Acta2 $^{-/-}$and Acta2 ${ }^{+/+}$HSCs. However, p-Erk1/2 was significantly greater in $\mathrm{Acta} 2^{+/+} \mathrm{HSCs}$ than in Acta $2^{-l-}$ HSCs in the presence of CCG-203971 or latrunculin-B (Figure 5F).

\section{SM $\alpha$-Actin Deficiency Leads to Decreased Liver Fibrosis in Vivo}

Finally, the response of $A c t a 2^{-/-}$mice to liver wound healing and the fibrotic response to chronic liver injury were examined. The effect of Acta 2 deficiency on stellate cell recruitment in carbon tetrachloride-induced liver fibrosis was first studied. Stellate cells were labeled with cellular retinol binding protein-1 (CRBP-1), a specific molecular marker for stellate cells in liver. In normal 
A

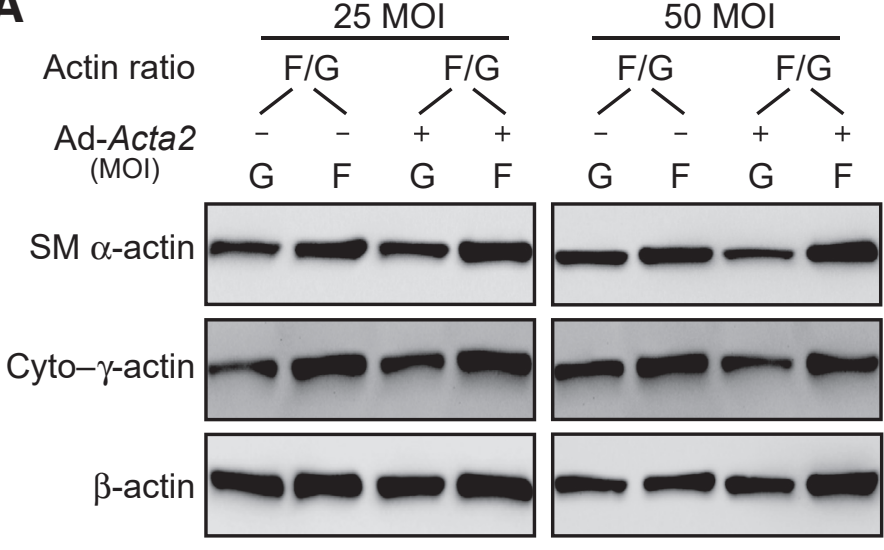

B C
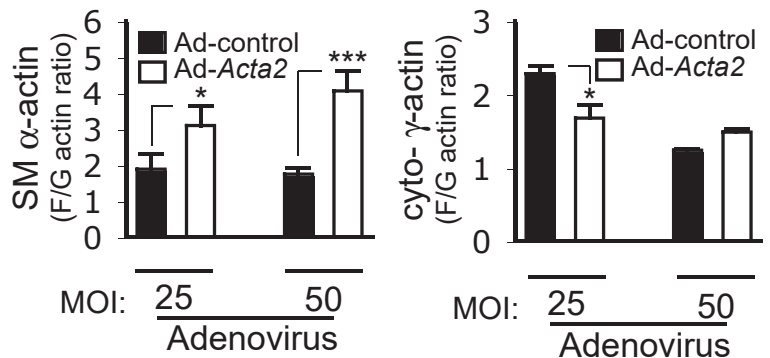

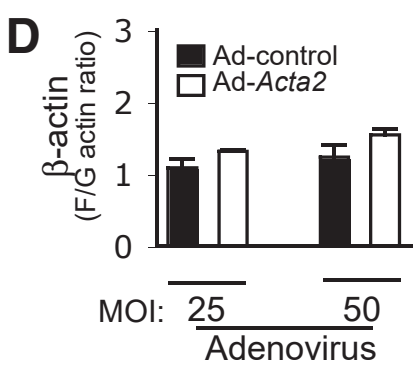

E
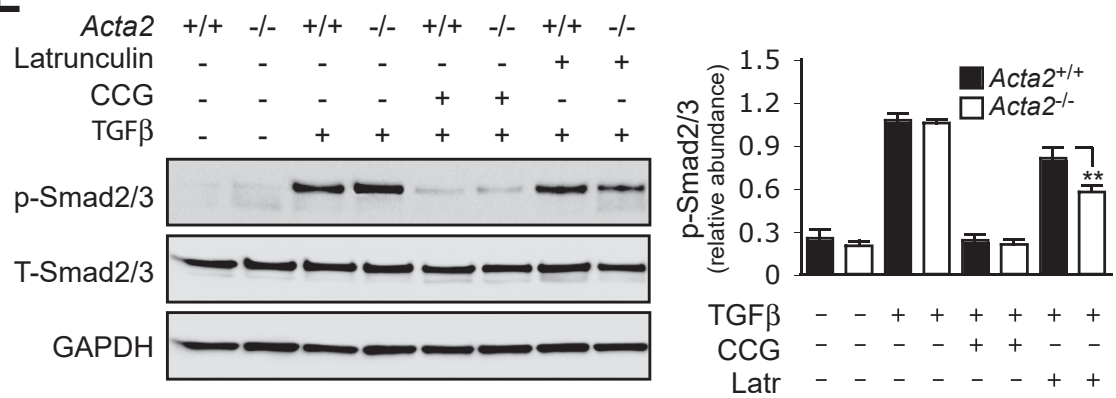

Figure 5 Smooth muscle (SM) $\alpha$-actin polymerization mediates transforming growth factor- $\beta$ (TGF- $\beta$ ) and ET-1 signaling. A: Rat hepatic stellate cells (HSCs) were exposed to Ad-control or Ad-SM $\alpha$-actin [25 or 50 multiplicity of infection (MOI)] for 3 days and incubated in $0.5 \%$ serum medium for 24 hours. Cells were harvested in actin stabilization buffer, and $\mathrm{F} / \mathrm{G}$-actin isoforms $(\mathrm{F} / \mathrm{G})$ were detected by immunoblotting with actin isoform specific antibodies. B-D: Quantification of F/Gactin ratios. $\mathbf{E}$ and $\mathbf{F}$ : $\mathrm{HSC}$ from $\mathrm{Acta}^{+/+}$and $A c t a 2^{-/-}$mice were cultured in standard medium for 5 days and then incubated in $0.5 \%$ serum medium with or without $20 \mu \mathrm{mol} / \mathrm{L}$ CCG-203971 (CCG) or $1 \mu \mathrm{mol} / \mathrm{L}$ latrunculin (Latr) for 24 hours. Cells were stimulated with TGF- $\beta$ for 1 hour (E) or ET-1 $(20 \mathrm{nmol} / \mathrm{L})$ for 30 minutes $(\mathbf{F})$, respectively. Whole-cell lysates were subjected to immunoblotting as indicated. Representative images and quantitative data are shown. $n=3 .{ }^{*} p<0.05$, $* * P<0.01$, and $* * * P<0.001$ for Acta $^{+/+}$versus Acta $^{-/-}$. cyto- $\gamma$-actin , cytoplasmic $\gamma$-actin.

ET-1

CCG

Latr $\square$ Acta2 ${ }^{+1+}$

Acta $2^{-1-}$

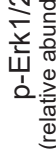
क 0.9 (迹 $0.3-$ 10 IIIII

GAPDH

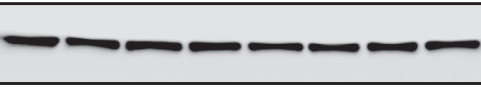

$-+++-$ liver, Acta $2^{-1-}$ mice had the same number of stellate cells as wild-type mice (Figure 6A). However, after liver injury, though there was a dramatic increase in the number of CRBP-1-positive $\mathrm{HSCs}$, particularly in portal areas in $\mathrm{Acta} 2^{+/+}$mice, there were substantially fewer CRBP-1-positive HSCs in Acta2 ${ }^{-1-}$ mice (Figure 6A). Another HSC molecular marker, desmin, was further examined, and the result was similar to CRBP-1 staining (Supplemental Figure S4).

Next, the effect of Acta2 deficiency on liver fibrogenesis in carbon tetrachloride-induced chronic liver injury was examined. Following six doses of carbon tetrachloride, COL $1 \alpha 1$ mRNA levels in whole liver of Acta $^{-1-}$ mice were also significantly decreased compared with Acta $2^{+/+}$mice (Figure 6B). Consistent with the expression of COL $1 \alpha 1$ mRNA, collagen labeled with Picrosirius Red in the livers of $A c t a 2^{-1-}$ mice was less than that in Acta $2^{+/+}$mice (Figure 6, C and D). It was further investigated whether Acta2 deficiency might alter the immune response during carbon tetrachloride-induced liver fibrogenesis by examining tumor necrosis factor $\alpha$ and IL-6 expression, two 
A
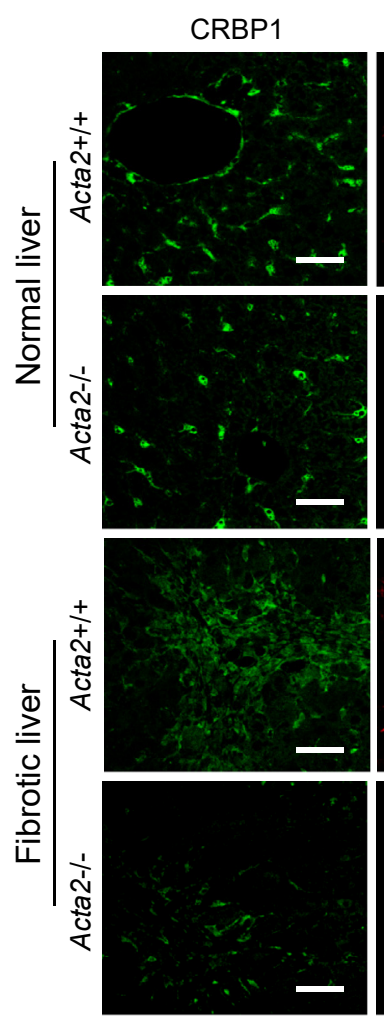

B

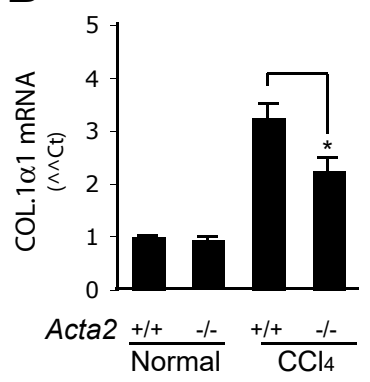

$\mathbf{E}$

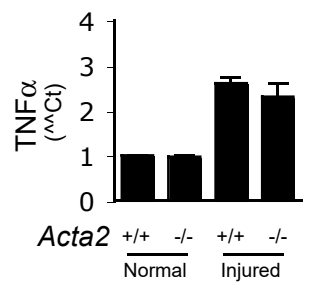

SM $\alpha$-actin
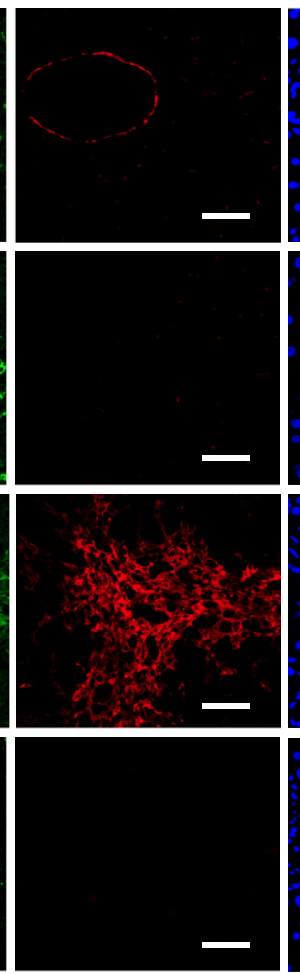

C
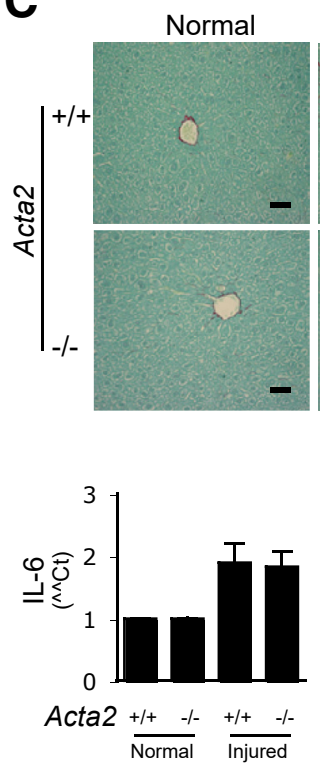
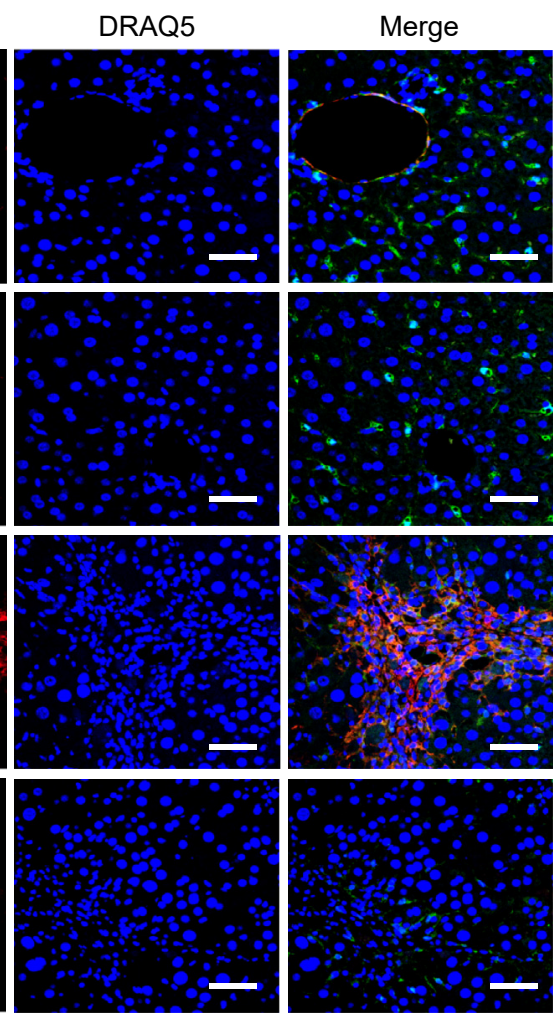

D

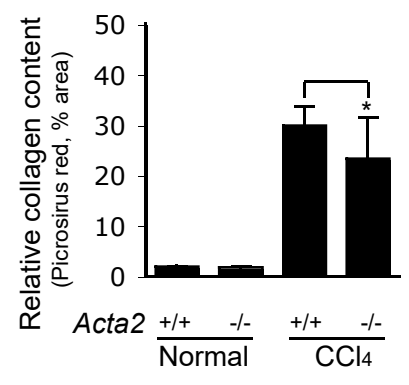

$\mathbf{F}$

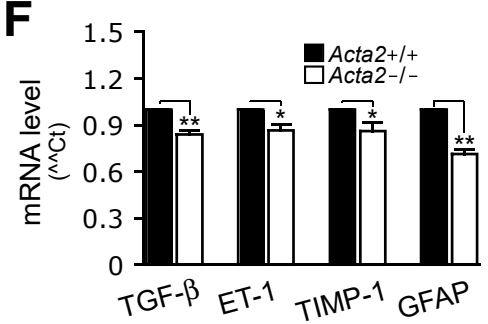

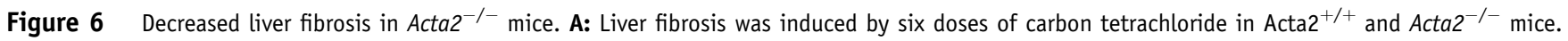
Control mice were gavaged with corn oil only. Whole-liver tissues were harvested and fixed in 10\% buffered formalin, and liver tissue sections were subjected to immunofluorescence staining as shown. B: Total RNA was isolated from whole-liver tissues, and real-time quantitative PCR was performed. C and D: Liver tissue sections were also stained with Picrosirius Red and collagen content were measured by quantitative histomorphometry. E: Tnfa and Il6 mRNA expression was measured by real-time quantitative PCR as in B. F: Acta2 ${ }^{+/+}$and $A c t a 2^{-/-}$mice were subjected to carbon tetrachloride-induced liver injury (4 doses) and in vivo activated $\mathrm{HSCS}$ were directly isolated to measure the indicated mRNAs. $n=4(\mathbf{A}-\mathbf{E}$, control); $n=4(\mathbf{F}$, carbon tetrachloride); $n=10$ (A-E, carbon tetrachloride). ${ }^{\star} P<0.05,{ }^{* *} P<0.01$ for $\mathrm{Acta}^{+/+}$versus $\mathrm{Acta}^{-/-}$. Scale bars $=100 \mu \mathrm{m}$.

cytokines important in the inflammatory response to liver injury. ${ }^{31}$ Tnfa and $I l 6$ mRNA levels in the livers of Acta2 $2^{-1-}$ mice were similar to that in $\mathrm{Acta} 2^{+/+}$mice (Figure 6E). Finally, Tgfb, ET-1, Gfap, and Timpl mRNA levels were examined in the HSCs isolated from carbon tetrachloride-induced fibrotic livers (Figure 6F). Taken together, these data indicate that SM $\alpha$-actin plays an important role in liver wound healing. 


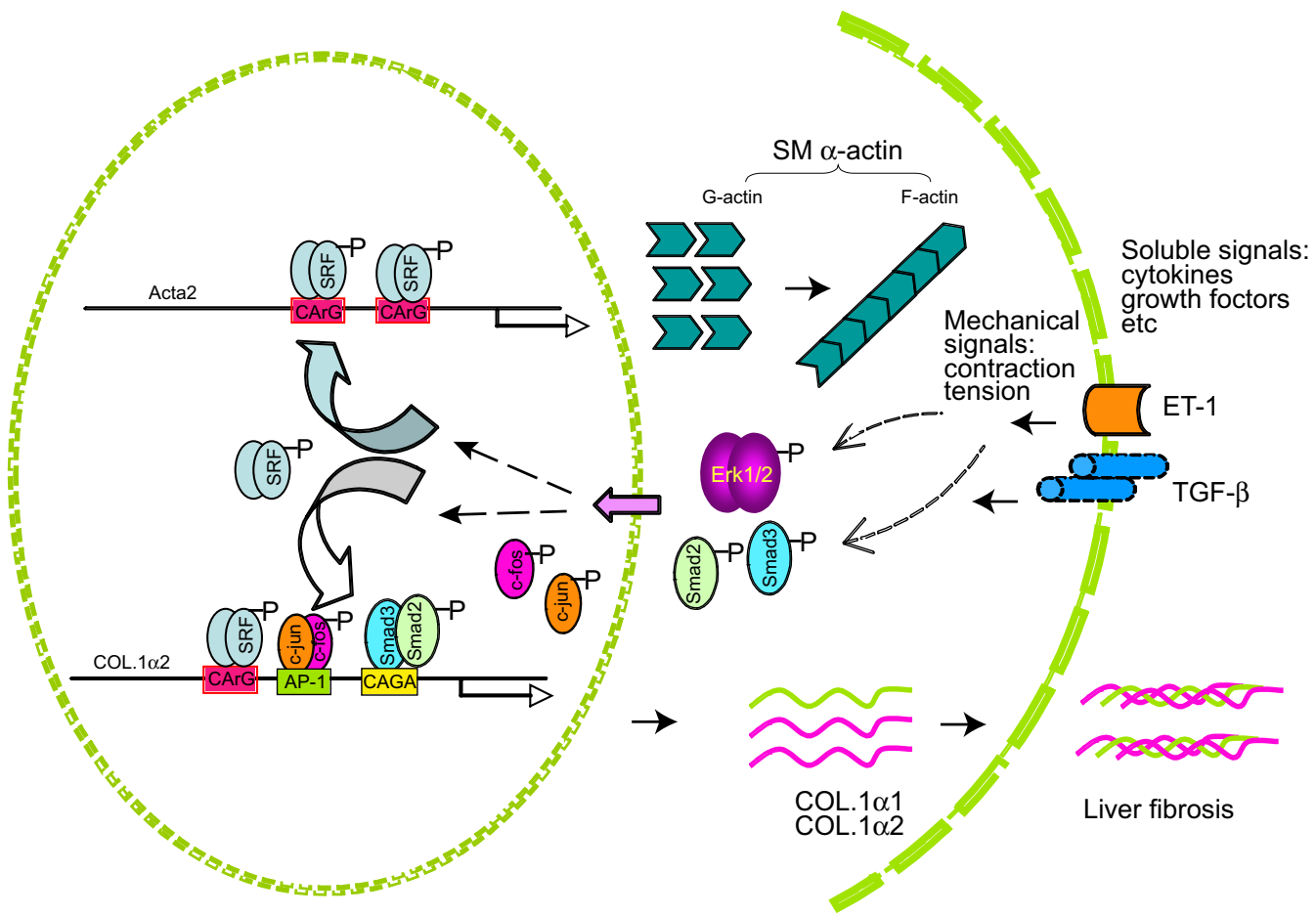

Figure 7 A proposed molecular mechanism underlying the effect of smooth muscle (SM) $\alpha$-actin on hepatic myofibroblast differentiation and liver fibrogenesis. SM $\alpha$-actin is encoded by Acta2 and transactivated by serum response factor (SRF) during hepatic stellate cell activation. This leads to actin polymerization and stress fiber formation, which not only serves as the functional actin cytoskeleton, but also plays an important role in transmission of mechanical signals to the nucleus to regulate COL1 expression. Additionally, signaling mediated by important soluble factors such as transforming growth factor- $\beta$ (TGF- $\beta$ ) and ET- 1 is impaired in Acta2-deficient hepatic stellate cells, contributing to reduced expression of COL1 and liver fibrosis in Acta2-deficient mice.

\section{Discussion}

Fibrosis is characterized by excessive ECM production, which primarily is synthesized by fibroblasts and myofibroblasts. ${ }^{1,32}$ SM $\alpha$-actin, not only defines the myofibroblasts lineage, but also has important functional effects, in particular in cell contraction. ${ }^{1,11}$ Here, it is further demonstrated that SM $\alpha$-actin also plays an important role in the regulation of COL1 expression, both at the whole-organ level $\left(\right.$ Acta2 $^{-1-}$ mice exhibit a decreased fibrotic response to liver wound healing during carbon tetrachloride-induced chronic liver injury) and in a cell culture model. The mechanism underlying the impaired fibrogenic response at a molecular level appears to be linked to disrupted fibrogenic signaling through the cytoskeleton (Figure 7).

Actins are essential components of the cytoskeleton in mammalian cells, and different actin isoforms perform unique cellular functions. ${ }^{33,34}$ Cytoplasmic $\beta$-actin, for example, appears to specially control cell growth and migration. ${ }^{28}$ Further, different cell types appear to be characterized by a unique profile of actin isoforms, which appears to impart specific functional and mechanical properties. An important example of this specificity is exhibited by myofibroblasts from dermal wound healing or kidney fibrosis, which express SM $\alpha$-actin, SM $\gamma$-actin, and skeletal muscle $\alpha$-actin. ${ }^{19,25}$ By contrast, mouse HSCs contain SM $\alpha$-actin and the cytoplasmic actins, but no SM $\gamma$-actin or skeletal muscle $\alpha$-actin. This likely explains the observation that SM $\alpha$-actin deficiency in these other cell types did not alter the cells' contractility. Further, fibrosis was not abrogated in vivo in skin or kidney fibrosis models. ${ }^{19,25}$ In HSCs, loss of SM $\alpha$-actin leads to up-regulation of the two cytoplasmic actin isoforms in activated Acta2 $^{-1-}$ HSCs (Figure 1). However, such compensatory regulation of cytoplasmic $\beta$ - or $\gamma$-actin isoforms did not rescue the functional defects such as cell contractility and fibrogenesis (Figures 2, A-D, and 6, $\mathrm{B}-\mathrm{D})$. This finding resembles $\beta$-actin-deficient primary mouse embryonic fibroblasts, which display compensatory expression of other actin isoforms, but could not restore cell migration defects. ${ }^{35}$ These findings suggest that SM $\alpha$-actin plays a critical role in the development of the typical actin cytoskeleton architecture in activated HSCs, and this appears to be important in the fibrogenic aspect of myofibroblast function (Figure 7). The data further support the concept that the actin cytoskeleton is dynamically linked to cell function (ie, during injury). ${ }^{36}$

Robust expression of the ECM constituent, COL1, is one of most prominent features in hepatic stellate cell activation and hepatic fibrosis. ${ }^{1}$ Although the molecular regulation of COL1 expression and biosynthesis is reasonably established, the molecular pathways underlying regulation of COL1 
expression, particularly via $S M \alpha$-actin cytoskeleton, remain to be explored. Here, it is shown that $\mathrm{SM} \alpha$-actin is involved in the regulation of multiple genes relevant to HSC activation and liver fibrosis, including GFAP, TIMPI, TGFB, and ET-1. Interestingly, lipid droplets appeared to have similar morphologic features in $\mathrm{Acta}^{-/-}$and Acta2 ${ }^{+/+}$HSCs (Figure 3, $\mathrm{A}-\mathrm{C}$ ); however, the functional implications of this finding are unknown. Importantly, Collal mRNA expression was significantly decreased in $\mathrm{Acta}^{-1-}$ stellate cells in response to TGF- $\beta$ or ET-1 stimulation compared with Acta2 ${ }^{+/+}$stellate cells (Figure 3D). COL1 protein levels in mouse stellate cells were not examined because suitable antibodies are not available. Further, the overexpression of SM $\alpha$-actin led to increased COL1 expression in rat stellate cells (Figure 3E). Interestingly, in overexpression experiments, there was an optimal dose-response relationship, in which an extremely high SM $\alpha$ actin F/G-actin ratio did not lead to as great of COL1 expression. These data suggest that at a cellular level, there is likely an optimal SM $\alpha$-actin concentration and F/G-actin ratio (or checkpoint) in control of COL1 expression. To our knowledge, this finding has not been previously reported.

TGF- $\beta$ and ET- 1 signaling pathways play a critical role in hepatic myofibroblast differentiation and function. ${ }^{29,30}$ The results in which decreased Smad2 and Erk1/2 phosphorylation was found in $A c t a 2^{-1-}$ stellate cells after stimulation with TGF- $\beta$ and ET-1 (and overexpression of SM $\alpha$-actin increased p-Smad2) (Figure 4) emphasize that the SM $\alpha$ actin cytoskeleton modulates TGF- $\beta / \mathrm{Smad} 2$ and ET-1/Erk1/ 2 signaling pathways, in turn regulating hepatic stellate cell activation and fibrogenesis. Although the molecular mechanism(s) underlying the SM $\alpha$-actin link to Smad2 and Erk1/2 phosphorylation remain open, the results showed that a mechanical signal transmitted by the SM $\alpha$-actin cytoskeleton is at play, because SM $\alpha$-actin polymerization was increased by increasing SM $\alpha$-actin levels (Figure 5, A and B), which was consistent with the increased COL1 expression (Figure 3E) and p-Smad2/3 (Figure 4C). On the other hand, disruption of actin polymerization, particularly SM $\alpha$-actin, abrogated TGF- $\beta /$ Smad 2 and ET-1/Erk $1 / 2$ signaling in activated HSCs (Figure 5, E and F). Thus, SM $\alpha$-actin-mediated mechanotransduction appears to exert a critical role in the regulation of COL1 expression in HSCs. ${ }^{36}$

HSC activation, proliferation, and fibrogenesis are prominent cellular and molecular features of liver fibrosis. ${ }^{1,37}$ Given the finding of reduced liver fibrosis in $\mathrm{Acta}^{-1-}$ mice after carbon tetrachloride-induced liver injury (Figure 6, B-D), it was not surprising to find a reduced number of CRBP1-positive HSCs (Figure 6A) or desmin-positive HSCs (Supplemental Figure S4) in fibrotic Acta2 ${ }^{-1-}$ mouse livers compared with that in fibrotic $\mathrm{Acta} 2^{+/+}$mouse livers. Although SM $\alpha$-actin isoform deficiency itself does not affect HSC proliferation or migration in vitro, in vivo activated Acta $2^{-1-}$ HSCs appear to display a reduced response to cellular internal (Figure 2D) and cellular surrounding environmental stimuli (such as TGF- $\beta$ and ET-1) compared with
Acta $2^{+/+}$HSCs during liver fibrogenesis (Figure $6 \mathrm{~F}$ ). These data emphasize the concept that, not only do hepatic myofibroblasts have a unique actin cytoskeletal composition, but also this cytoskeletal makeup yields unique functional properties compared with myofibroblasts from other organs (ie, kidney), consistent with previous data highlighting hepatic myofibroblast heterogeneity. ${ }^{38}$

In summary, wound healing is a dynamic process in which multiple cellular and molecular processes come into play. SM $\alpha$-actin is not only important in hepatic stellate cell contractility, but the SM $\alpha$-actin cytoskeleton also transmits mechanical signals to the nucleus to regulate COL1 expression (Figure 7). Thus, these new data reveal a novel mechanism for SM $\alpha$-actin-mediated control of fibrogenesis and imply that targeting the SM $\alpha$-actin cytoskeleton could be a specific approach to treatment of liver fibrosis.

\section{Acknowledgments}

We thank Nate Weymouth for technical support with immunohistochemistry; Yingyu Ren with animal genotyping, cell isolation, and culture; and Dr. Andy Wessels (Department of Regenerative Medicine and Cell Biology, Medical University of South Carolina) for help with Zeiss Axio Imager M2 microscope. Acta2-deficient 129SV/C57 mice were a kind gift from Dr. Robert Schwartz.

D.C.R. conceived and designed the study, interpreted data, supervised the study, and wrote and revised the manuscript; Q.D. performed experiments and analyzed data; Z.S. conceived and designed the study, performed experiments, analyzed data, and wrote and revised the manuscript.

\section{Supplemental Data}

Supplemental material for this article can be found at https://doi.org/10.1016/j.ajpath.2019.07.019.

\section{References}

1. Rockey DC, Bell PD, Hill JA: Fibrosis-a common pathway to organ injury and failure. N Engl J Med 2015, 373:95-96

2. Pellicoro A, Ramachandran P, Iredale JP, Fallowfield JA: Liver fibrosis and repair: immune regulation of wound healing in a solid organ. Nat Rev Immunol 2014, 14:181-194

3. Li B, Wang JH: Fibroblasts and myofibroblasts in wound healing: force generation and measurement. J Tissue Viability 2011, 20: $108-120$

4. Hinz B, Phan SH, Thannickal VJ, Galli A, Bochaton-Piallat ML, Gabbiani G: The myofibroblast: one function, multiple origins. Am J Pathol 2007, 170:1807-1816

5. Habiel DM, Hogaboam CM: Heterogeneity of fibroblasts and myofibroblasts in pulmonary fibrosis. Curr Pathobiol Rep 2017, 5: $101-110$

6. Mederacke I, Hsu CC, Troeger JS, Huebener P, Mu X, Dapito DH, Pradere JP, Schwabe RF: Fate tracing reveals hepatic stellate cells as dominant contributors to liver fibrosis independent of its aetiology. Nat Commun 2013, 4:2823 
7. Iwaisako K, Jiang C, Zhang M, Cong M, Moore-Morris TJ, Park TJ, Liu X, Xu J, Wang P, Paik YH, Meng F, Asagiri M, Murray LA, Hofmann AF, Iida T, Glass CK, Brenner DA, Kisseleva T: Origin of myofibroblasts in the fibrotic liver in mice. Proc Natl Acad Sci U S A 2014, 111:E3297-E3305

8. Dominguez R, Holmes KC: Actin structure and function. Annu Rev Biophys 2011, 40:169-186

9. Sandbo N, Dulin N: Actin cytoskeleton in myofibroblast differentiation: ultrastructure defining form and driving function. Transl Res 2011, 158:181-196

10. Hinz B: Formation and function of the myofibroblast during tissue repair. J Invest Dermatol 2007, 127:526-537

11. Rockey DC, Weymouth N, Shi Z: Smooth muscle alpha actin (Acta2) and myofibroblast function during hepatic wound healing. PLoS One 2013, 8:e77166

12. Hinz B, Celetta G, Tomasek JJ, Gabbiani G, Chaponnier C: Alphasmooth muscle actin expression upregulates fibroblast contractile activity. Mol Biol Cell 2001, 12:2730-2741

13. Hinz B, Dugina V, Ballestrem C, Wehrle-Haller B, Chaponnier C: Alpha-smooth muscle actin is crucial for focal adhesion maturation in myofibroblasts. Mol Biol Cell 2003, 14:2508-2519

14. Goffin JM, Pittet P, Csucs G, Lussi JW, Meister JJ, Hinz B: Focal adhesion size controls tension-dependent recruitment of alpha-smooth muscle actin to stress fibers. J Cell Biol 2006, 172:259-268

15. Harburger DS, Calderwood DA: Integrin signalling at a glance. J Cell Sci 2009, 122:159-163

16. Lindahl GE, Chambers RC, Papakrivopoulou J, Dawson SJ, Jacobsen MC, Bishop JE, Laurent GJ: Activation of fibroblast procollagen alpha 1(I) transcription by mechanical strain is transforming growth factor-beta-dependent and involves increased binding of CCAAT-binding factor (CBF/NF-Y) at the proximal promoter. J Biol Chem 2002, 277:6153-6161

17. Wipff PJ, Rifkin DB, Meister JJ, Hinz B: Myofibroblast contraction activates latent TGF-beta1 from the extracellular matrix. J Cell Biol 2007, 179:1311-1323

18. Shi Z, Rockey DC: Upregulation of the actin cytoskeleton via myocardin leads to increased expression of type 1 collagen. Lab Invest 2017, 97:1412-1426

19. Takeji M, Moriyama T, Oseto S, Kawada N, Hori M, Imai E, Miwa T: Smooth muscle alpha-actin deficiency in myofibroblasts leads to enhanced renal tissue fibrosis. J Biol Chem 2006, 281: 40193-40200

20. Schildmeyer LA, Braun R, Taffet G, Debiasi M, Burns AE, Bradley A, Schwartz RJ: Impaired vascular contractility and blood pressure homeostasis in the smooth muscle alpha-actin null mouse. FASEB J 2000, 14:2213-2220

21. Yata Y, Gotwals P, Koteliansky V, Rockey DC: Dose-dependent inhibition of hepatic fibrosis in mice by a TGF-beta soluble receptor: implications for antifibrotic therapy. Hepatology 2002, 35: $1022-1030$
22. Shi Z, Rockey DC: Interferon-gamma-mediated inhibition of serum response factor-dependent smooth muscle-specific gene expression. J Biol Chem 2010, 285:32415-32424

23. Weymouth N, Shi Z, Rockey DC: Smooth muscle alpha actin is specifically required for the maintenance of lactation. Dev Biol 2012, $363: 1-14$

24. Jophlin LL, Koutalos Y, Chen C, Shah V, Rockey DC: Hepatic stellate cells retain retinoid-laden lipid droplets after cellular transdifferentiation into activated myofibroblasts. Am J Physiol Gastrointest Liver Physiol 2018, 315:G713-G721

25. Tomasek JJ, Haaksma CJ, Schwartz RJ, Howard EW: Whole animal knockout of smooth muscle alpha-actin does not alter excisional wound healing or the fibroblast-to-myofibroblast transition. Wound Repair Regen 2013, 21:166-176

26. Nakamura Y, Hirano S, Suzuki K, Seki K, Sagara T, Nishida T: Signaling mechanism of TGF-betal-induced collagen contraction mediated by bovine trabecular meshwork cells. Invest Ophthalmol Vis Sci 2002, 43:3465-3472

27. Kharbanda KK, Rogers DD 2nd, Wyatt TA, Sorrell MF, Tuma DJ: Transforming growth factor-beta induces contraction of activated hepatic stellate cells. J Hepatol 2004, 41:60-66

28. Bunnell TM, Burbach BJ, Shimizu Y, Ervasti JM: beta-Actin specifically controls cell growth, migration, and the G-actin pool. Mol Biol Cell 2011, 22:4047-4058

29. Khimji AK, Rockey DC: Endothelin and hepatic wound healing. Pharmacol Res 2011, 63:512-518

30. Meng XM, Nikolic-Paterson DJ, Lan HY: TGF-beta: the master regulator of fibrosis. Nat Rev Nephrol 2016, 12:325-338

31. Koyama Y, Brenner DA: Liver inflammation and fibrosis. J Clin Invest 2017, 127:55-64

32. Wynn TA: Cellular and molecular mechanisms of fibrosis. J Pathol 2008, 214:199-210

33. Perrin BJ, Ervasti JM: The actin gene family: function follows isoform. Cytoskeleton (Hoboken) 2010, 67:630-634

34. Bunnell TM, Ervasti JM: Structural and functional properties of the actin gene family. Crit Rev Eukaryot Gene Expr 2011, 21:255-266

35. Tondeleir D, Lambrechts A, Muller M, Jonckheere V, Doll T, Vandamme D, Bakkali K, Waterschoot D, Lemaistre M, Debeir O, Decaestecker C, Hinz B, Staes A, Timmerman E, Colaert N, Gevaert K, Vandekerckhove J, Ampe C: Cells lacking beta-actin are genetically reprogrammed and maintain conditional migratory capacity. Mol Cell Proteomics 2012, 11:255-271

36. Chiquet M, Gelman L, Lutz R, Maier S: From mechanotransduction to extracellular matrix gene expression in fibroblasts. Biochim Biophys Acta 2009, 1793:911-920

37. Seki E, Schwabe RF: Hepatic inflammation and fibrosis: functional links and key pathways. Hepatology 2015, 61:1066-1079

38. Magness ST, Bataller R, Yang L, Brenner DA: A dual reporter gene transgenic mouse demonstrates heterogeneity in hepatic fibrogenic cell populations. Hepatology 2004, 40:1151-1159 